\title{
LA EXCEPCIÓN PRELIMINAR: FALTA DE COMPETENCIA DE LA CORTE INTERAMERICANA ¿UN MECANISMO EFECTIVO DE DEFENSA ESTATAL?*
}

\section{Andrés González Serrano**}

Fecha de Recibido: 15 de marzo de 2011

Fecha de Aprobación: 13 de abril de 2011

Articulo Resultado de Investigación

\section{Resumen}

El presente artículo demostrará que la excepción preliminar "falta de competencia en razón a la materia", sí es un mecanismo de defensa estatal efectivo. Sin embargo, también se podrá evidenciar que este mecanismo se ha tornado ineficaz debido que los agentes estatales de los diferentes Estados Parte de la Convención, son quienes han restado importancia a la excepción, al interponerla de forma no adecuada ante la Corte Interamericana de Derechos Humanos.

\section{Palabras clave}

Excepción preliminar - Falta de competencia en razón a la materia - Corte Interamericana de Derechos Humanos - Comisión Interamericana de Derechos Humanos.

\section{PRELIMINARY EXCEPTION: JURISDICTION ABSENCE OF THE INTERAMERICAN COURT. ¿A REAL ABSTRACT MECHANISM OF STATE DEFENSE?}

\begin{abstract}
In this article it will be demonstrated that the jurisdiction absence as concern to the subject is really an effective state defense. It will be however proved, that this mechanism has became inefficient due it the fact that the officers of the law from the different states, that the integrate the convention, don't consider important exception and in this way they interpose it., in a no suitable way, in the face of the Interamerican Human rights Court.
\end{abstract}

\section{Key Words}

Preliminary exception, jurisdiction absence as concern to the subject, Interamerican Human rights Court, Interamerican Commission of the Human rights

* Artículo resultado de la investigación "Defensa Estatal ante la Corte Interamericana de Derechos Humanos - Líneas jurisprudenciales desde la perspectiva procedimental - Excepciones preliminares.", realizada por la Universidad Militar Nueva Granada. El autor agradece la colaboración de la Auxiliar de Investigación Laurent Daniella Melo Durán, en la elaboración del estado del arte y de las fichas jurisprudenciales.

** Abogado Universidad Militar Nueva Granada. Especialista en Docencia Universitaria de la Universidad Militar Nueva Granada. Magíster en Derecho Administrativo de la Universidad Militar Nueva Granada. Docente Investigador de la Universidad Militar Nueva Granada. andres.gonzalez@unimilitar.edu.co. 


\section{A EXCEÇÃO PRELIMINAR: FALTA DE COMPETÊNCIA DA CORTE INTERAMERICANA. UM MECANISMO EFETIVO DE DEFESA ESTATAL?}

\section{Resumo}

O presente artigo demonstrará que a exceção preliminar "falta de competência em razão da matéria" sim é um mecanismo efetivo de defesa estatal. No entanto, também poderá ser evidenciado que este mecanismo se tornou ineficaz dado que os agentes estatais dos diferentes Estados Parte da Convenção são aqueles não deram a devida importância à exceção, ao colocá-la de forma não adequada diante da Corte Interamericana de Direitos Humanos.

\section{Palavras-chave}

Exceção preliminar, falta de competência em razão da matéria, Corte Interamericana de Direitos Humanos, Comissão Interamericana de Direitos Humanos.

\section{INTRODUCCIÓN}

La Corte Interamericana de Derechos Humanos, ha manifestado que las excepciones preliminares son un mecanismo de defensa estatal. Sin embargo, hecha la recolección, lectura, análisis y clasificación de las sentencias desde 1987 hasta 2009 proferidas por el máximo tribunal interamericano, se evidencia que las excepciones, en su generalidad han sido desestimadas y declaradas inadmisibles, tornándolas en inefectivas.

Por lo anterior, nace la necesidad de desarrollar un proyecto de investigación titulado Defensa Estatal en el Sistema Interamericano - Líneas Jurisprudenciales desde la Perspectiva Procedimental - Excepciones preliminares; el cual tiene como objetivo principal, identificar la tradición argumentativa de la Corte al momento de fallar sentencias de excepciones preliminares, con el fin de poder establecer si las mismas son ó no son un medio de defensa estatal en el sistema interamericano.

Dentro del proyecto antes mencionado existen diferentes objetivos específicos, entre ellos el construir una línea jurisprudencial sobre competencia en razón a la materia, para identificar el precedente de la Corte Interamericana en la presente excepción preliminar $\mathrm{y}$, de esta forma poder identificar los diferentes criterios de proce- dencia o no de la misma. Es por ello que el presente artículo posee como pregunta problema ¿La excepción preliminar falta de competencia en razón a la materia, ha sido un mecanismo de defensa estatal efectivo al incoarla ante la Corte Interamericana de Derechos Humanos?

Para responder a la pregunta planteada, se utilizó un método jurídico, analítico y descriptivo, y como estrategia metodológica la construcción de una línea jurisprudencial, con las sentencias proferidas por el máximo tribunal desde 1987 a 2009, debido que los fallos proferidos en la materia por la Corte sólo han sido doce.

Es necesaria la construcción de la línea jurisprudencial, porque la misma establece de forma objetiva el precedente y los requisitos de procedencia de la excepción. Criterios fijados por la Corte Interamericana y no establecidos en la Convención Americana, es decir, que son construcción de los jueces del sistema interamericano de protección de derechos humanos. Es por lo anterior, que las diferentes sentencias analizadas se han clasificado en hito: aquella que responde de forma concreta y correcta la pregunta problema planteada; fundadora de línea: se caracteriza por contestar la pregunta problema planteada pero fija al menos un criterio que será reconocido posteriormente en la hito $y$, confirmadora de principio: son 
aquellas que repiten y no aportan criterios diferentes a los ya establecidos en sentencias precedentes. (LÓPEZ: 2008: 139 - 192)

El artículo se desarrolla en tres partes: (1) observaciones iníciales, se explica qué es una excepción preliminar y qué es competencia en razón a la materia; (2) estudio de casos - construcción de la línea jurisprudencial, se construye la línea jurisprudencial con las sentencias emitidas por la Corte desde el 1987 a 2009 y (3) observaciones finales concluyentes, se demuestra que la excepción si es un mecanismo efectivo de defensa estatal.

\section{OBSERVACIONES PRELIMINARES}

La Convención Americana sobre Derechos $\mathrm{Hu}-$ manos (en adelante Convención - CADH) consagra la posibilidad de sometimiento de un caso ante la Corte tanto por la Comisión Interamericana de Derechos Humanos (en adelante Comisión $\mathrm{CIDH}$ ) como un Estado Parte de la Convención¹. Entre tanto, cuando el Estado demandado es notificado del sometimiento del caso posee derecho de defenderse y le confieren un término de dos meses improrrogables para que presente su escrito de contestación, tanto del informe de sometimiento del caso presentado por la Comisión como del escrito de solicitudes argumentos y pruebas presentado por los peticionarios. ${ }^{2}$

1 Convención Americana sobre Derechos Humanos. Suscrita en San José de Costa Rica el 22 de noviembre de 1969, en la Conferencia Especializada Interamericana sobre Derechos Humanos. Artículo 51-1 "Si en el plazo de tres meses, a partir de la remisión a los Estados interesados del informe de la Comisión, el asunto no ha sido solucionado o sometido a la decisión de la Corte por la Comisión o por el Estado interesado, aceptando su competencia, la Comisión podrá emitir, por mayoría absoluta de votos de sus miembros, su opinión y conclusiones sobre la cuestión sometida a su consideración" y 61-1 "Sólo los Estados partes y la Comisión tienen derecho a someter un caso a la decisión de la Corte".

2 Reglamento de la Corte Interamericana de Derechos Humanos. Aprobado por la Corte en su LXXXV Período Ordinario de Sesiones celebrado del 16 al 28 de noviembre de 2009. Artículo 41-1 "En la
El escrito de contestación que presenta el Estado puede contener alegatos tanto de forma: presentación de excepciones preliminares; como de fondo: demostrar el pleno cumplimiento de las obligaciones de respeto, garantía y adecuación; así como, la no vulneración de los derechos humanos contemplados en la convención y, reparaciones.

Dentro de las excepciones preliminares que puede interponer el Estado ante la Corte son de dos tipos: admisibilidad y competencia. Los factores de competencia que posee la CORIDH se subdividen en cuatro: tiempo, persona, lugar y materia.

Es esta última excepción, falta de competencia en razón a la materia, la que se será objeto de análisis en el presente artículo con el fin de demostrar los elementos o criterios que deben tener en cuenta los agentes estatales al momento de incoarla como mecanismo de defensa estatal.

Si bien, la Convención Americana de Derechos Humanos, no establece dentro de su cuerpo jurídico el concepto de excepción preliminar, la Corte Interamericana de Derechos Humanos, bajo su competencia contenciosa ha establecido que es aquella que tiene como virtud no seguir con el trámite de fondo.

La Corte ha señalado que una excepción preliminar tiene por finalidad obtener una decisión que prevenga o impida el análisis sobre el fondo del aspecto cuestionado o del caso en su conjunto. Por ello, el planteo debe satisfacer las características jurídicas esenciales en contenido y finalidad que le confieran el carácter de excepción preliminar. Los planteamientos que no tengan tal naturaleza, como por

contestación el Estado indicará: a. si acepta los hechos y las pretensiones o si los contradice; b. las pruebas ofrecidas debidamente ordenadas, con indicación de los hechos y argumentos sobre los cuales versan; c. la propuesta e identificación de los declarantes y el objeto de su declaración. En el caso de los peritos, deberán además remitir su hoja de vida y sus datos de contacto; d. los fundamentos de derecho, las observaciones a las reparaciones y costas solicitadas, así como las conclusiones pertinentes". 
ejemplo los que se refieren al fondo de un caso, pueden ser formulados mediante otros actos procesales previstos en la Convención Americana, pero no bajo la figura de una excepción preliminar ${ }^{3}$

En otros términos, las excepciones preliminares son el medio de defensa que posee un Estado para que el caso no llegue a análisis de vulneración o no de derechos humanos y/o de cumplimiento o no de las obligaciones convencionales; es la posibilidad que el caso no prosiga con su trámite regular por aspectos netamente formales, de requisitos procesales. Un claro ejemplo de lo anterior se evidencia en el caso Cayara. El Estado de Perú propuso la excepción preliminar "presentación extemporánea de la demanda", debido que la Comisión sometió el caso ante la Corte pasado los tres meses que le permite la Convención contados desde el traslado del informe preliminar al Estado para su fiel cumplimiento.

Entre la fecha del retiro del caso y la presentación de la nueva demanda, transcurren más de siete meses. Independientemente de si el plazo original vencía el 31 de mayo o el 5 de junio de 1991, no hay duda de que el 14 de febrero de 1992, excede con mucho los límites de temporalidad y razonabilidad que la Corte ha dicho que informan el procedimiento. Si la Comisión entendió que el Gobierno peruano había solicitado el retiro, tal petición, por razonable que fuere, no podía ser atendida por estar agotado el plazo que la Convención concede para intro-

3 Corte Interamericana de Derechos Humanos. Caso Castañeda Gutman Vs. México. Sentencia de Excepciones Preliminares, Fondo, Reparaciones y Costas. Serie C No. 184. Sentencia de 6 de agosto de 2008. Párrafo. 39. Corte Interamericana de Derechos Humanos. Caso Tristán Donoso Vs. Panamá. Sentencia de Excepciones Preliminares, Fondo, Reparaciones y Costas. Serie C No. 193. Sentencia de 27 de enero de 2009. Párrafo. 15. Corte Interamericana de Derechos Humanos. Caso Escher y Otros vs. Brasil. Sentencia de Excepciones preliminares, Fondo, Reparaciones y Costas. Serie C No. 200. Sentencia de 6 de julio de 2009. Párrafo 15. ducir una demanda y, como queda dicho, no es uno de aquellos factores que hubieran podido implicar la suspensión de los términos. (CORIDH : 1993: 3 de febrero, prf, 60)

La Corte declarará, sin haber entrado a la materia de fondo a que se refiere la demanda de la Comisión, que ésta fue extemporánea. Sin embargo, de la lectura del artículo 51 se infiere que una declaración de este orden no puede implicar la neutralización de los demás mecanismos de tutela contemplados en la Convención Americana y que, en consecuencia, la Comisión conserva todas las demás atribuciones que le confiere ese artículo, lo que, por lo demás, coincide con el objeto y fin del tratado. (CORIDH, 1993, prf. 61).

De igual manera, la Corte estimó la excepción preliminar falta de competencia en razón al tiempo en el Caso Alfonso Martín del Campo Dodd Vs. Estados Unidos Mexicanos. El Estado argumentaba que la Corte no era competente para conocer de hechos ocurridos con anterioridad al 16 de diciembre de 1998 y que los actos de Tortura que plantean las presuntas víctimas y la Comisión ocurrieron en el mes de mayo de 1992, además son típicos delitos de ejecución instantánea, por lo cual quedan fuera del alcance de la competencia de la Corte. Entre tanto la Comisión alegó que la detención arbitraria y la denegación de justicia son de carácter permanente y se encontraban vigentes a la fecha de concesión de competencia a la Corte. Sin embargo, la Corte IDH manifestó:

La Corte debe determinar si el supuesto delito de tortura alegado por la Comisión Interamericana y los representantes de la presunta víctima y sus familiares es un delito de ejecución instantánea o un delito de ejecución continua o permanente. Cada acto de tortura se ejecuta o consume en sí mismo, y su ejecución no se extiende en el tiempo, por lo que el acto o actos de tortura alegados en perjuicio del señor Martín 
del Campo quedan fuera de la competencia de la Corte por ser un delito de ejecución instantáneo y haber supuestamente ocurrido antes del 16 de diciembre de 1998. Asimismo, las secuelas de la tortura, alegadas por los representantes de la presunta víctima y sus familiares, no equivalen a un delito continuo. Cabe señalar que la Corte ha reiterado en su jurisprudencia constante su rechazo absoluto a la tortura y el deber de los Estados Partes de investigar, procesar y sancionar a los responsables de la misma. (CORIDH.: 2004: 3 de septiembre, prf, 78)

Es necesario que el Tribunal señale con toda claridad sobre esta materia que si el delito alegado fuera de ejecución continua o permanente, la Corte tendría competencia para pronunciarse sobre los actos o hechos ocurridos con posterioridad al reconocimiento de la jurisdicción de la Corte. Pero en un caso como el presente, el supuesto delito causa de la violación alegada (tortura) fue de ejecución instantánea, ocurrió y se consumó antes del reconocimiento de la competencia contenciosa. En lo que atañe a la investigación de dicho delito, la misma se produjo y se reabrió en varias ocasiones. Ello ocurrió con posterioridad al reconocimiento de competencia contenciosa de la Corte, pero ni la Comisión ni los representantes de la presunta víctima han aportado elementos sobre afectaciones ocurridas que permitan identificar violaciones específicas al debido proceso sobre las cuales la Corte hubiera podido conocer. (CORIDH, 2004: 3 de septiembre: prf, 79)

En razón de lo anterior, la Corte estima que debe aplicarse el principio de la irretroactividad de las normas internacionales consagrado en la Convención de Viena sobre el Derecho de los Tratados y en el derecho internacional general, $y$ de acuerdo con los términos en que México reconoció la competencia contenciosa de la Corte, acoge la excepción preliminar "ratione temporis" interpuesta por el Estado para que la Corte no conozca supuestas violaciones a la Convención Americana ni a la Convención Interamericana contra la Tortura ocurridas antes del 16 de diciembre de 1998. (CORIDH: 2004: 3 de septiembre, prf, 85)

Ahora bien, la Convención no estableció que se era competencia en razón a la materia, ni tampoco que era excepción preliminar; la Corte bajo su función contenciosa se ha encargado de fijar los criterios para establecer cuando el máximo tribunal posee o no, competencia en razón a la misma.

La Competencia en razón a la materia es la facultad que posee la Corte IDH de pronunciarse sobre el cumplimiento o no, de lo consagrado en un instrumento interamericano, por parte de un Estado Parte de dicho instrumento y por ende declarar su responsabilidad internacional. Es por lo anterior que el artículo 62 de la Convención establece:

1. Todo Estado parte puede, en el momento del depósito de su instrumento de ratificación o adhesión de esta Convención, o en cualquier momento posterior, declarar que reconoce como obligatoria de pleno derecho y sin convención especial, la competencia de la Corte sobre todos los casos relativos a la interpretación o aplicación de esta Convención.

2. La declaración puede ser hecha incondicionalmente, o bajo condición de reciprocidad, por un plazo determinado o para casos específicos. Deberá ser presentada al Secretario General de la Organización, quien transmitirá copias de la misma a los otros Estados miembros de la Organización y al Secretario de la Corte.

3. La Corte tiene competencia para conocer de cualquier caso relativo a la interpretación y aplicación de las 
disposiciones de esta Convención que leseasometido, siemprequelosEstados partes en el caso hayan reconocido o reconozcan dicha competencia, ora por declaración especial, como se indica en los incisos anteriores, ora por convención especial.

En otros términos, es necesario que exista un reconocimiento de los Estados hacia la Corte para que ella pueda realizar un examen, tanto del instrumento ratificado como de los hechos que enmarcan un caso de violación de derechos humanos, y de esta forma poder declarar la responsabilidad de ese Estado; de lo contrario, carecería de competencia y el Estado demandado podría interponer la excepción preliminar, falta de competencia en razón a la materia.

Ahora bien, teniendo claro los criterios fijados por la Corte IDH para que una excepción se caracterice como preliminar y la procedencia de la misma cuando se pretenda excepcionar por falta de competencia en razón a la materia; se entrará a analizar si la excepción propuesta por los Estado Parte ha sido incoada acorde a los estándares interamericanos fijados por la Corte como mecanismo de defensa estatal.

\section{ESTUDIO DE CASOS - CONSTRUCCIÓN DE LA LÍNEA JURISPRUDENCIAL. (LÓPEZ: 2008: 141) ${ }^{4}$}

Los casos que serán sujetos de análisis de acuerdo a la pregunta problema ¿La excepción preliminar falta de competencia en razón a la materia, ha sido un mecanismo de defensa estatal efectivo al incoarla ante la Corte Interamericana de Derechos Humanos? son: ${ }^{5}$ Caso Blake Vs.

4 "una línea jurisprudencial es una pregunta o problema jurídico bien definido, bajo el cual se abre un espacio abierto de posibles respuestas".

5 Se aclara que los hechos relevantes para la primera etapa de la investigación son los relacionados con los aspectos procesales o de forma y no, los relacionados
Guatemala, Caso Castillo Petruzzi y otros Vs. Perú, Caso las Palmeras Vs. Colombia, Caso Benjamin y otros Vs. Trinidad y Tobago, Caso Constantine y otros Vs. Trinidad y Tobago, Caso Hilaire Vs. Trinidad y Tobago, Caso de las Hermanas Serrano Cruz Vs. El Salvador, Caso Cantoral Huamaní y García Santa Cruz Vs. Perú, Caso Heliodoro Portugal vs. Panamá, y Caso Tristàn Donoso vs. Panamá.

\subsection{Caso Blake Vs. Guatemala. (CORIDH: 1996: 2 de julio, prf, 12) ${ }^{6}$}

\begin{tabular}{|l|l|l|}
\hline No & $\begin{array}{l}\text { ¿La excepción preliminar: falta } \\
\text { de competencia en razón a la } \\
\text { materia, ha sido un mecanismo de } \\
\text { defensa estatal efectivo al incoarla } \\
\text { ante la Corte Interamericana de } \\
\text { Derechos Humanos? }\end{array}$ & Si \\
\hline$*$ & \\
\hline
\end{tabular}

La presente sentencia es ubicada en la parte centro izquierda de la construcción de la línea jurisprudencial por ser una sentencia fundadora de línea, debido que la decisión de la Corte responde la pregunta problema planteada, pero no de forma concreta.

con los aspectos de fondo. Sin embargo, la persona que se encuentre interesada para conocer los hechos de fondo los podrán ver a pie de página con su correspondiente cita de forma resumida.

6 Según la demanda, el señor Nicholas Chapman Blake, partió el 26 de marzo de 1985 junto con el señor Griffith Davis, hacia la pequeña aldea de El Llano, lugar al que llegaron el 28 de marzo de 1985. El objeto del viaje era recabar información para escribir un artículo sobre uno de los sectores de la guerrilla guatemalteca. Ese mismo día, la Patrulla Civil de El Llano, bajo la Comandancia de Mario Cano, interrogó a los señores Blake y Davis "sobre el propósito del viaje que realizaban". Años más tarde se estableció que luego de solicitar instrucciones a los oficiales de la guarnición militar de Las Majadas, Mario Cano ordenó a tres miembros de su patrulla, que detuvieran a Blake y a Davis, que los llevaran a un lugar llamado Los Campamentos, en la frontera con el Departamento de El Quiché y les expresó: "pueden matarlos si quieren". Al llegar al lugar indicado, los mataron y arrojaron los cuerpos en una maleza muy tupida, al lado del sendero", y los cubrieron con troncos de árboles "a efectos de hacerlos desaparecer". 
El Estado de Guatemala, al momento de incoarla expresó que los hechos narrados por la Comisión fueron ejecutados por miembros de Patrullas de Autodefensa Civil, los cuales no son agentes estatales y por tanto su actuar son ilícitos penales más no violaciones a los derechos y libertades reconocidos en la Convención. (CORIDH: 1996: 2 de julio, prf, 25,41)

La base argumentativa de la Corte para desestimar la excepción se ciño en establecer que lo alegado por el Estado no era de carácter preliminar, por cuanto establecer si las Patrullas de Autodefensa Civil, son o no agentes estatales ó su actuar es imputable al Estado se debe analizar en la etapa de fondo. ${ }^{7}$ (C. I. D. H.: 1996: 2 de julio, prf, 43).

\subsection{Caso Castillo Petruzzi y otros Vs. Perú. (CORIDH: 1998: 4 de septiembre, prf, 2$)^{8}$}

\begin{tabular}{|l|l|l|}
\hline No & $\begin{array}{l}\text { ¿La excepción preliminar: falta } \\
\text { de competencia en razón a la } \\
\text { materia, ha sido un mecanismo de } \\
\text { defensa estatal efectivo al incoarla } \\
\text { ante la Corte Interamericana de } \\
\text { Derechos Humanos? }\end{array}$ & \\
\hline & $*$ & \\
\hline
\end{tabular}

La presente sentencia es ubicada en la parte centro izquierda de la construcción de la línea jurisprudencial por ser una sentencia fundadora

7 Cuando la Corte habla del Fondo hace referencia a la violación o no de un derecho humano. Entre tanto la Forma se relaciona con los requisitos de admisibilidad y competencia del sometimiento del caso.

8 De acuerdo con la demanda, el Perú violó el derecho a la nacionalidad de los señores Jaime Francisco Castillo Petruzzi, María Concepción Pincheira Sáez, Lautaro Enrique Mellado Saavedra y Alejandro Astorga Valdés, al juzgarlos y condenarlos por el delito de "traición a la patria”, de conformidad con el Decreto-Ley No. 25.659, aunque el Perú no es su patria. Asimismo, la Comisión aseveró que dichas personas no fueron juzgadas por un juez o tribunal competente, independiente e imparcial, con violación de las garantías judiciales, pues todos fueron procesados y condenados a cadena perpetua por un tribunal "sin rostro", perteneciente a la justicia militar. de línea, debido que la decisión de la Corte responde la pregunta problema planteado, pero no de forma concreta.

El Estado de Perú, alegó que la Corte no posee competencia en razón a la materia debido que lo pretendido por la Comisión busca modificar y dejar sin efecto una decisión soberana emitida por un organismo jurisdiccional, hecho que esta fuera del alcance de las facultades de la Corte por ser decisiones definitivas e inmodificables. (CORIDH: 1998: 4 de septiembre, prf, 100)

Para el máximo tribunal, el anterior argumento no fue estimado y declaró inadmisible la excepción preliminar. La decisión tuvo fundamento en el concepto de soberanía, en la medida que el Estado de Perú suscribió y ratificó la Convención Americana y en consecuencia aceptó las obligaciones convencionales consagradas en ésta. También dejó claro, que si las presuntas víctimas (Jaime Francisco Castillo Petruzzi, María Concepción Pincheira Sáez, Lautaro Enrique Mellado Saavedra y Alejandro Astorga Valdés) hubiesen actuado en contra de las disposiciones de la Convención y de la ley nacional a la que deben sujetarse, puede acarrear consecuencias penales, lo cual no releva al Estado de cumplir las obligaciones que éste asumió como Estado Parte de la Convención. (CORIDH: 1998: 4 de septiembre, prf, 101, 102, 103, 104)

En otros términos, la Corte IDH dejó claro que la facultad que posee es para realizar un análisis de compatibilidad de los procedimientos internos adelantados en contra de las presuntas víctimas con lo establecido en instrumentos del Sistema Interamericano y, de forma específica con la Convención Americana. (CORIDH: 1998: 4 de septiembre, prf, 101, 102, 103, 104)

\subsection{Caso las Palmeras Vs. Colombia. (CORIDH: 2000: 4 de febrero, prf, 2) ${ }^{9}$}

9 El 23 de enero de 1991 el Comandante de la Policía de Putumayo habría ordenado a miembros de la Policía llevar a cabo una operación armada en la localidad de Las Palmeras. En la mañana de ese mismo día se 


\begin{tabular}{|l|l|l|}
\hline No & $\begin{array}{l}\text { ¿La excepción preliminar: falta } \\
\text { de competencia en razón a la } \\
\text { materia, ha sido un mecanismo de } \\
\text { defensa estatal efectivo al incoarla } \\
\text { ante la Corte Interamericana de } \\
\text { Derechos Humanos? }\end{array}$ & \\
\hline & $\mathrm{Si}$ \\
& \\
\hline
\end{tabular}

La presente sentencia es ubicada en la parte derecha de la construcción de la línea jurisprudencial por ser sentencia hito, debido que la decisión de la Corte responde de forma concreta la pregunta planteada, claro está, bajo las sentencias que son de análisis. La Corte estableció criterios que deben tenerse en cuenta al momento de proponer la excepción para que proceda.

El Estado propuso la excepción de falta de competencia en razón a la materia, debido que la Comisión Interamericana solicitó a la Corte que declarara responsable al Estado de Colombia por violar el artículo 3 común de los Convenios de Ginebra. Colombia argumentó su excepción, manifestando que son los Estados quienes le conceden competencia tanto a la Comisión como a la Corte y la misma se encuentra limitada a lo establecido en la Convención Americana, por tanto, la Comisión como la Corte deben pronunciarse únicamente sobre la competencia que le han sido atribuida de manera taxativa. (CORIDH: 2000: 4 de febrero, prf, 28).

Argumento precedente aceptado por la Corte, que estableció criterios de procedencia de la excepción como mecanismo de defensa estatal efectivo. En otros términos, el máximo tribunal determinó que la competencia de los órganos del sistema intera-

encontraban en la escuela unos niños para iniciar sus clases y dos trabajadores que reparaban un tanque, cuando miembros de la fuerza pública empezaron a disparar hiriendo a uno de los niños. La policía detuvo al maestro de la escuela y a varias personas más y los habrían ejecutado extrajudicialmente, por lo cual los miembro de la Policía y ejército hicieron numerosos esfuerzos para justificar la conducta, por lo cual vistieron con uniformes de militares los cadáveres de las víctimas quemado sus ropas y amedrentado a los testigos del caso. Presentaron siete cadáveres como pertenecientes a subversivos muertos en un presunto enfrentamiento. mericano se encuentra circunscrita a la concedida por los Estados Parte de la Convención.

El hecho de que los Estados miembros de la Organización de los Estados Americanos deban observar de buena fe los Convenios de Ginebra y ajustar su legislación interna al cumplimiento de esos instrumentos no le confiere competencia a la Comisión para deducir responsabilidad del Estado con base en ellos. (CORIDH: 2000: 4 de febrero, prf, 33)

Si bien la Comisión Interamericana tiene amplias facultades como órgano de promoción y protección de los derechos humanos, de la Convención Americana se desprende, con toda claridad, que el procedimiento iniciado en casos contenciosos ante la Comisión que culmine en una demanda ante la Corte, debe referirse precisamente a los derechos protegidos por dicha Convención. (CORIDH: 2000: 4 de febrero, prf, 34)

No obstante, la Corte hizo claridad, que los órganos del sistema interamericano, poseen competencia para pronunciarse de las violaciones de los derechos humanos, contemplados en otros instrumentos diferentes a la Convención, siempre y cuando, el Estado se la haya concedido. (CORIDH: 2000: 4 de febrero, prf, 34) ${ }^{10}$

(...) Se exceptúan de esta regla, los casos en que otra Convención, ratificada por el Estado, confiere competencia a la Comisión o a la Corte Interamericanas para conocer de violaciones de los derechos protegidos por dicha Convención, como, por ejemplo, la Convención Interamericana sobre

10 Ver: Corte Interamericana de Derechos Humanos. Caso de la "Panel Blanca" (Paniagua Morales y otros) Vs. Guatemala. Sentencia de Fondo. Serie C No 37. Sentencia de 8 de marzo de 1998. Párrafo 136. Corte Interamericana de Derechos Humanos. Caso de los "Niños de la Calle" (Villagrán Morales y otros) Vs. Guatemala. Sentencia de Fondo. Serie C No 63. Sentencia de 19 de noviembre de 1999. Párrafo 252. La Corte declaró la violación de la Convención Interamericana para Prevenir y Sancionar la Tortura. 
Desaparición Forzada de Personas. (CORIDH: 2000: 4 de febrero, prf, 30)

De la misma forma, la Corte manifestó, que su competencia para realizar un examen de compatibilidad con la Convención no se encuentra limitada, es decir, que posee la facultad de examinar si una norma de carácter interno o internacional, aplicada por un Estado Parte en un caso concreto, es o no compatible con la misma, así haya sido decidido por el orden interno. (CORIDH: 2000: 4 de febrero, prf, 32,33)

\subsection{Caso Hilaire Vs. Trinidad y Tobago (CORIDH: 2001: 1 de septiembre, $C$, 80. prf, 2) ${ }^{11}$ - Caso Benjamin y otros Vs. Trinidad y Tobago (CORIDH: 2001: 1 de septiembre, C. 81. prf, 2) ${ }^{12}$ - Caso Constantine y otros Vs. Trinidad y Tobago (CORIDH: 2001: 1 de septiembre, C. 82. prf, 2) ${ }^{13}$}

\begin{tabular}{|l|l|l|}
\hline \multirow{3}{*}{ No } & $\begin{array}{l}\text { ¿La excepción preliminar: falta } \\
\text { de competencia en razón a la } \\
\text { materia, ha sido un mecanismo de } \\
\text { defensa estatal efectivo al incoarla } \\
\text { ante la Corte Interamericana de } \\
\text { Derechos Humanos? }\end{array}$ & \\
\hline & Si & \\
\hline
\end{tabular}

11 El 29 de mayo de 1995 el señor Hilaire fue condenado a pena de muerte, junto con sus dos co-imputados, la señora Indravani Ramjattan y el señor Denny Baptiste, por el asesinato del señor Alexander Jordan, ocurrido el 13 de febrero de 1991. Dicha condena fue emitida por la Primera Sala Penal de Port of Spain Assizes, Trinidad y Tobago.

12 Los señores Peter Benjamin, Krishendath Seepersad, Allan Phillip, Narine Sooklal, Amir Mowlah, Mervyn Parris y Francis Mansingh, fueron condenados a la pena de muerte obligatoria, de la misma manera el Estado no les proporciono el derecho efectivo a solicitar la amnistía, el indulto o la conmutación de la pena.

La Constitución de Trinidad y Tobago establece un Comité Consultivo de Indulto, que tiene a su cargo estudiar y hacer recomendaciones al Ministro de Seguridad Nacional sobre si un delincuente sentenciado a muerte debe beneficiarse de la discreción presidencial del indulto en virtud de la Constitución mencionada.

13 Los señores a George Constantine, Wenceslaus James, Denny Baptiste, Clarence Charles, Keiron Thomas,
Las presentes sentencias son ubicadas en la parte centro izquierda de la construcción de la línea jurisprudencial, por ser sentencias confirmadoras de principio del caso Castillo Petruzzi, debido que la decisión de la Corte responde la pregunta problema planteada, pero no de forma concreta.

El Estado al momento de incoar la excepción, manifestó que la Corte no poseía competencia en razón a la materia para conocer de las decisiones definitivas internas, alegando la reserva presentada por Trinidad y Tobago, al momento de depositar el 28 de mayo de 1991 el instrumento de adhesión.

Con respecto al artículo 62 de la Convención, el Gobierno de la República de Trinidad y Tobago, reconoce la jurisdicción obligatoria de la Corte Interamericana de Derechos Humanos que se estipula en dicho artículo sólo en la medida en que tal reconocimiento sea compatible con las secciones pertinentes de la Constitución de la República de Trinidad y Tobago, y siempre que una sentencia de la Corte no contravenga, establezca o anule derechos o deberes existentes de ciudadanos particulares. (CORIDH: 2001: 1 de septiembre, C. 82 . prf, 43. 42)

Argumento no plausible para la Corte y por tanto desestima la excepción preliminar. La base de decisión del máximo tribunal se circunscribió en el examen de compatibilidad de la reserva hecha por Trinidad y Tobago. Como resultado del mismo, se estableció que la reserva realizad por Trinidad y Tobago es contraria al objeto y fin de la Convención, en la medida que limita el actuar de la Corte a lo

Anthony Garcia, Wilson Prince, Darrin Roger Thomas, Mervyn Edmund, Samuel Winchester, Martin Reid, Rodney Davis, Gangadeen Tahaloo, Noel Seepersad, Wayne Matthews, Alfred Frederick, Natasha De Leon, Vijay Mungroo, Phillip Chotalal, Joey Ramiah y Naresh Boodram, Nigel Mark, Wilberforce Bernard y Steve Mungroo, fueron condenados a la pena de muerte obligatoria, de la misma manera el Estado no les proporciono el derecho efectivo a solicitar la amnistía, el indulto o la conmutación de la pena. 
establecido en la Constitución del Estado, es decir, que subordina la facultad del tribunal al ordenamiento interno, hecho que restringe de forma ilegitima el fin del sistema interamericano.

Como se ha visto, la pretendida "reserva" tiene dos partes. La primera se orienta a limitar el reconocimiento de la competencia contenciosa de la Corte, en el sentido de que dicho reconocimiento sólo valdrá como tal en la medida en que "sea compatible con las secciones pertinentes" de la Constitución de Trinidad y Tobago. Estas expresiones admiten muchas interpretaciones. Sin embargo, para la Corte es claro que no puede dárseles un alcance de acuerdo con el cual constituyan un impedimento para que este Tribunal juzgue si el Estado violó o no alguna disposición de la Convención. La segunda parte de la pretendida restricción condiciona el "reconocimiento" del Estado de la competencia contenciosa de la Corte a que las sentencias de ésta "no contravenga[n], establezca[n] o anule[n] derechos o deberes existentes de ciudadanos particulares" (sic). Nuevamente, además de que el significado preciso de esta condición no es claro, es indudable que no puede ser utilizado con el propósito de suprimir la competencia de la Corte para conocer y decidir una demanda en relación con una supuesta violación de las obligaciones convencionales del Estado. (CORIDH: 2001: 1 de septiembre, C. 82. prf, 86, 77)

Esta Corte observa que el instrumento de aceptación, por parte de Trinidad y Tobago, de la competencia contenciosa del Tribunal, no encuadra en las hipótesis previstas en el artículo 62.2 de la Convención Americana. Tiene un alcance general, que termina por subordinar la aplicación de la Convención al derecho interno de Trinidad y Tobago en forma total y según lo dispongan sus tribunales nacionales. Todo esto implica que este instrumento de aceptación es manifiestamente incompatible con el ob- jeto y fin de la Convención. Por lo tanto, no existe en el citado artículo disposición alguna que faculte a Trinidad y Tobago para formular la restricción que hizo. (CORIDH: 2001, 1 de septiembre, C. 82. prf, 88, 79).

En otros términos, la Corte aclaró, a los Estados Parte de la Convención, que sí posee competencia para revisar los procesos internos, verificando, si los mismos, se sustanciaron conforme a lo establecido en la Convención Americana, más no sujetándose al examen del cumplimiento o no de éstos de sus leyes internas.

\subsection{Caso de las Hermanas Serrano Cruz Vs. El Salvador. (CORIDH: 2004: 23 de noviembre. prf, 2) ${ }^{14}$}

\begin{tabular}{|l|l|l|}
\hline \multirow{2}{*}{ No } & $\begin{array}{l}\text { ¿La excepción preliminar: falta } \\
\text { de competencia en razón a la } \\
\text { materia, ha sido un mecanismo de } \\
\text { defensa estatal efectivo al incoarla } \\
\text { ante la Corte Interamericana de } \\
\text { Derechos Humanos? }\end{array}$ & \\
\hline & \multicolumn{1}{|c|}{$*$} & \\
\hline
\end{tabular}

La presente sentencia es ubicada en la parte central de la construcción de la línea jurisprudencial por ser sentencia confirmadora de principio, debido que la decisión de la Corte responde de forma concreta la pregunta planteada y reitera la ratio decidendi del caso las Palmeras, es decir, indica nuevamente criterios que deben tenerse en cuenta al momento de proponer la excepción falta de competencia en razón a la materia.

14 La Comisión Interamericana expuso en su demanda que a partir del 2 de junio de 1982 se dio la supuesta captura, secuestro y desaparición forzada de las entonces niñas Ernestina y Erlinda Serrano Cruz, quienes tenían 7 y 3 años de edad, respectivamente, cuando fueron supuestamente capturadas por militares integrantes del Batallón Atlacatl del Ejército salvadoreño durante un operativo militar conocido como Operación Limpieza o la guinda de mayo, el cual se llevó a cabo, entre otros, en el Municipio de San Antonio de la Cruz, departamento de Chalatenango, desde el 27 de mayo hasta el 9 de junio de 1982. En dicho operativo supuestamente "participaron unos catorce mil militares. 
El Estado propuso la excepción falta de competencia en razón a la materia, porque los hechos del presente caso, se constituyeron o enmarcaron bajo el análisis del Derecho Internacional Humanitario, instrumentos que se encuentran fuera de la esfera de competencia de la Corte IDH para pronunciarse de su violación e incumplimiento.

Los hechos del presente caso se desarrollaron cuando el Estado de El Salvador pasaba por uno de los momentos más difíciles y críticos de su historia (1979-1992), cuando las fuerzas de oposición y las fuerzas gubernamentales se encontraban en claro enfrentamiento. La situación de tensión interna de 1979 a 1992, se ubicó como un conflicto armado no internacional y se reguló por la normas del Derecho Internacional Humanitario, específicamente por los cuatro Convenios de Ginebra de 1949 y sus Protocolos Adicionales de 1977, de los cuales El Salvador es Parte. El Comité Internacional de la Cruz Roja (CICR) intervino con el propósito de brindar protección y asistencia a las víctimas de la guerra y se reconoció como aplicable y vigente el Derecho Internacional Humanitario, independientemente de cómo se haya denominado el conflicto. (CORIDH: 2004: 23 de noviembre. prf, 108-a)

Sin embargo, la Corte desestimó la excepción propuesta por el Estado del Salvador, argumentando que los hechos relacionados entre 1979 a 1992, no serán objeto de pronunciamiento en la presente sentencia, por carecer de competencia en razón al tiempo debido que el Estado le concedió competencia para pronunciarse sobre violaciones de derechos humanos ocurridas después de 1995.

Entre tanto, el máximo tribunal, dejó claro que no posee competencia para declarar la responsabilidad internacional de un Estado miembro de la OEA y/o Parte de la Convención Americana, por violaciones de los derechos humanos contemplados en los Convenios de Ginebra ó normas que forman parte del cuerpo jurídico del Derecho Internacional Humanitario, pero, sí la posee para interpretar y dar mayor alcance al cuerpo jurídico de la Convención Americana.

En su jurisprudencia la Corte ha establecido claramente que tiene la facultad de interpretar las normas de la Convención Americana a luz de otros tratados internacionales, para lo cual en reiteradas oportunidades ha utilizado normas de otros tratados de derechos humanos ratificadas por el Estado demandado, para dar contenido y alcance a la normativa de la Convención. En este sentido, este Tribunal en su jurisprudencia constante ha resuelto que al dar interpretación a un tratado no sólo se toman en cuenta los acuerdos e instrumentos formalmente relacionados con éste (inciso segundo del artículo 31 de la Convención de Viena), sino también el sistema dentro del cual se inscribe (inciso tercero del artículo 31). En dicha jurisprudencia, la Corte ha indicado que esta orientación tiene particular importancia para el Derecho Internacional de los Derechos Humanos, que ha avanzado sustancialmente mediante la interpretación evolutiva de los instrumentos internacionales de protección. Estos parámetros permiten a la Corte utilizar las normas del Derecho Internacional Humanitario, ratificadas por el Estado demandado, para dar contenido y alcance a las normas de la Convención Americana. ${ }^{15}$

15 Corte Interamericana de Derechos Humanos. Caso de las Hermanas Serrano Cruz Vs. El Salvador. Sentencia Excepciones Preliminares. Op. Cit., Párrafo 119. Ver: Corte Interamericana de Derechos Humanos. Caso Tibi Vs. Ecuador. Sentencia de Excepciones Preliminares, Fondo, Reparaciones y Costas. Serie C No. 114. Sentencia de 7 de septiembre de 2004. Párrafo 144. Corte Interamericana de Derechos Humanos. Caso "Instituto de Reeducación del Menor" Vs. Paraguay. Sentencia Excepciones Preliminares, Fondo, Reparaciones y Costas. Serie C No. 112. Sentencia de 2 de septiembre de 2004. Párrafo 148. Corte Interamericana de Derechos Humanos. Caso de los Hermanos Gómez Paquiyauri Vs. Perú. Sentencia Fondo, Reparaciones y Costas. Serie C No. 110. Sentencia de 8 de julio de 2004. Párrafos. 165 y 166. 


\subsection{Caso Cantoral Huamaní y García Santa Cruz Vs. Perú. (CORIDH: 2007: 10 de julio. prf, 2) ${ }^{16}$}

\begin{tabular}{|c|c|c|}
\hline No & $\begin{array}{l}\text { ¿La excepción preliminar: falta } \\
\text { de competencia en razón a la } \\
\text { materia, ha sido un mecanismo de } \\
\text { defensa estatal efectivo al incoarla } \\
\text { ante la Corte Interamericana de } \\
\text { Derechos Humanos? }\end{array}$ & $\mathrm{Si}$ \\
\hline & , & \\
\hline
\end{tabular}

La presente sentencia es ubicada en la parte central de la construcción de la línea jurisprudencial por ser sentencia confirmadora de principio, debido que la decisión de la Corte responde de forma concreta la pregunta planteada y reitera la ratio decidendi del caso Palmeras, es decir, la Corte reafirma los criterios que deben tenerse en cuenta al momento de proponer la excepción falta de competencia en razón a la materia.

El Estado de Perú, al momento de incoar la excepción, manifestó que la Corte no poseía competencia en razón a la materia para pronunciarse sobre las presuntas violaciones de la Convención Interamericana para Prevenir y Sancionar la Tortura, debido que no se podía interpretar que los artículos 25 y 27 de la Convención Americana le concedieron dicha competencia. (CORIDH: 2007: 10 de julio. prf, 10)

Argumento no aceptado por la Corte, reiterando su precedente e indicando que posee competencia tanto para interpretar, aplicar y declarar la responsabilidad de la Convención

16 La demanda se refiere a los alegados secuestro, tortura y ejecución extrajudicial de Saúl Isaac Cantoral Huamaní y Consuelo Trinidad García Santa Cruz el día 13 de febrero de 1989, en Lima, Perú, y a la impunidad total en que se encuentran tales hechos. La Comisión señaló la importancia de someter el presente caso a la Corte puesto que han transcurrido más de 17 años sin que los familiares de las presuntas víctimas hayan conseguido conocer la verdad sobre las violaciones de los derechos de las presuntas víctimas, y sin que sus responsables hayan sido sancionados.
Americana, como de otro instrumento, cuando un Estado le haya concedido competencia. ${ }^{17}$

Preceptos que el Perú cumplió, debido que posee la calidad de Estado Parte del instrumento Convención Interamericana para Prevenir y Sancionar la Tortura, desde el 28 de marzo de 1991. (CORIDH: 2007: 10 de julio. prf, 12)

\subsection{Caso Heliodoro Portugal vs. Panamá. (CORIDH: 2008: 12 de agosto. prf, 2) ${ }^{18}$}

\begin{tabular}{|l|l|l|}
\hline \multirow{N}{*}{ No } & $\begin{array}{l}\text { ¿La excepción preliminar: falta } \\
\text { de competencia en razón a la } \\
\text { materia, ha sido un mecanismo de } \\
\text { defensa estatal efectivo al incoarla } \\
\text { ante la Corte Interamericana de } \\
\text { Derechos Humanos? }\end{array}$ & \\
\hline & \multicolumn{1}{|c|}{$*$} & \\
\hline
\end{tabular}

La presente sentencia es ubicada en la parte central de la construcción de la línea jurisprudencial

17 Ver: Corte Interamericana de Derechos Humanos. Caso del Penal Miguel Castro Castro Vs Perú. Sentencia Fondo, Reparaciones y Costas. Serie C No 160. Sentencia de 25 de noviembre de 2006. Párrafo 266. Corte Interamericana de Derechos Humanos. Caso Vargas Areco Vs Paraguay. Sentencia Fondo, Reparaciones y Costas. Serie C No 155. Sentencia de 26 de septiembre de 2006. Párrafo 94. Corte Interamericana de Derechos Humanos. Caso Baldeón García Vs Perú. Sentencia Fondo, Reparaciones y Costas. Serie C No 147. Sentencia de 6 de abril de 2006. Párrafo 162. Corte Interamericana de Derechos Humanos. Caso Gutiérrez Soler Vs Colombia. Sentencia Fondo, Reparaciones y Costas. Serie C No 132. Sentencia de 12 de septiembre de 2005.Párrafo 54.

18 La demanda somete a la jurisdicción de la Corte las presuntas violaciones cometidas por el Estado por la supuesta desaparición forzada y ejecución extrajudicial del señor Heliodoro Portugal, la supuesta falta de investigación y sanción de los responsables de tal hecho y la supuesta falta de reparación adecuada en favor de sus familiares. Según la demanda de la Comisión, el 14 de mayo de 1970 Heliodoro Portugal se encontraba en un café conocido como "CocaCola", ubicado en la ciudad de Panamá, donde fue abordado por un grupo de individuos vestidos de civil, quienes lo obligaron a subir a un vehículo que luego partió con rumbo desconocido. La Comisión alegó que agentes del Estado participaron en dichos hechos, los cuales ocurrieron en una época en la que Panamá se encontraba gobernada por un régimen militar. 
por ser sentencia confirmadora de principio, debido que la decisión de la Corte responde de forma concreta la pregunta planteada y reitera la ratio decidendi de nuestra sentencia hito, es decir, determina nuevamente criterios que deben tenerse en cuenta al momento de proponer la excepción falta de competencia en razón a la materia.

El Estado de Panamá, propuso la excepción y la base argumentativa de la misma se circunscribió en señalar que la Corte no poseía competencia para conocer del presunto incumplimiento de adecuación del ordenamiento interno al interamericano, de forma específica del tipo penal desaparición forzada, toda vez, la función contenciosa no consagra la presente facultad, además, que el delito de desaparición forzada se encuentra consagrado en el código penal vigente. (CORIDH: 2008: 12 de agosto. prf, 54)

Precedente argumento no aceptado por la Corte, y reitera su jurisprudencia en dos aspectos. Primero, que el alegato del Estado no es en sí mismo propio de excepciones preliminares, debido que no tiene por finalidad obtener una decisión que prevenga o impida el análisis sobre el fondo. Segundo, manifiesta que sí posee competencia contenciosa para analizar el incumplimiento del deber de adecuación del sistema interno al interamericano, y no sólo se restringe a la consultiva; por tanto puede realizar examen de compatibilidad de la legislación interna, específicamente, del tipo penal desaparición forzada con la Convención Americana y la Convención sobre Desaparición Forzada las cuales tiene fuerza vinculante desde 1990 y 1996 respectivamente para el Estado de Panamá. (CORIDH, 2008, 12 de agosto. prf, 61)

De la misma forma, el tribunal argumenta, que el examen de fondo de la presunta violación se circunscribirá en analizar, si la falta de adecuación hasta la fecha ha provocado una investigación bajo un tipo penal inapropiado y si dicha tipificación se ajusta a lo dispuesto en el artículo III de la Convención sobre Desaparición Forzada. (CORIDH, 2008, 12 de agosto. prf, 58)

\subsection{Caso Tristán Donoso vs. Panamá. (CORIDH, 2009, 27 de enero. prf, 2) ${ }^{19}$}

\begin{tabular}{|c|c|c|}
\hline No & $\begin{array}{l}\text { ¿La excepción preliminar: falta } \\
\text { de competencia en razón a la } \\
\text { materia, ha sido un mecanismo de } \\
\text { defensa estatal efectivo al incoarla } \\
\text { ante la Corte Interamericana de } \\
\text { Derechos Humanos? }\end{array}$ & $\mathrm{Si}$ \\
\hline & * & \\
\hline
\end{tabular}

La presente sentencia es ubicada en la parte central de la construcción de la línea jurisprudencial por ser sentencia confirmadora de principio, debido que la decisión de la Corte responde de forma concreta la pregunta planteada y reitera la ratio decidendi de nuestra sentencia hito, es decir, determina nuevamente criterios que deben tenerse en cuenta al momento de proponer la excepción falta de competencia en razón a la materia.

El Estado de Panamá, propuso la excepción y la base argumentativa de la misma se circunscribió, en señalar, que la Corte no poseía competencia contenciosa para conocer de la reparación solicitada por la Comisión de adecuar el sistema interno al interamericano, de forma específica el ordenamiento jurídico penal, al artículo 13 de la Convención Americana, ya que la pretensión aludida puede ser reconocida por la Corte, únicamente, en ejercicio de su función consultiva. (CORIDH, 2009, 27 de enero. prf, 12)

Argumento no aceptado por la Corte reiterando dos aspectos de su jurisprudencia. Primero, que el alegato del Estado no es en sí mismo propio

19 Según indicó la Comisión, la demanda se refiere a la alegada interceptación, grabación y divulgación de una conversación telefónica del abogado Santander Tristán Donoso; la posterior apertura de un proceso penal por delitos contra el honor como [supuesta] represalia a las denuncias del señor Tristán Donoso sobre la referida grabación y divulgación; la falta de investigación y sanción de los responsables de tales hechos, y la falta de reparación adecuada. 
de excepciones preliminares, debido que no tiene por finalidad obtener una decisión que prevenga o impida el análisis sobre el fondo. Segundo, manifiesta que sí posee competencia contenciosa, no sólo consultiva, para analizar la pretensión de la Comisión de adecuación del sistema interno al interamericano y por tanto, dicho examen se realizará en la etapa de reparaciones y costas. (CORIDH: 2009, 27 de enero. prf, 17)

Teniendo en cuenta los casos antes analizados, la línea la línea jurisprudencial construida sería:

\begin{tabular}{|c|c|c|}
\hline No & $\begin{array}{c}\text { ¿La excepción preliminar: falta de competencia en razón a la materia, } \\
\text { ha sido un mecanismo de defensa estatal efectivo al incoarla ante la } \\
\text { Corte Interamericana de Derechos Humanos? }\end{array}$ & $\mathrm{Si}$ \\
\hline \multicolumn{3}{|c|}{ * Fundadora de línea } \\
\hline \multicolumn{3}{|c|}{ Caso Blake Vs. Guatemala } \\
\hline \multicolumn{3}{|c|}{ * Fundadora de línea } \\
\hline \multicolumn{3}{|c|}{ Caso Castillo Petruzzi y otros Vs. Perú } \\
\hline \multirow{2}{*}{\multicolumn{3}{|c|}{$\begin{array}{r}* \text { Hito } \\
\text { Caso las Palmeras Vs. Colombia }\end{array}$}} \\
\hline & & \\
\hline \multicolumn{3}{|c|}{ * Confirmadora de principio } \\
\hline \multicolumn{3}{|c|}{ Caso Hilaire Vs. Trinidad y Tobago } \\
\hline \multicolumn{3}{|c|}{ * Confirmadora de principio } \\
\hline \multicolumn{3}{|c|}{ Caso Benjamin y otros Vs. Trinidad y Tobago } \\
\hline \multicolumn{3}{|c|}{ * Confirmadora de principio } \\
\hline \multicolumn{3}{|c|}{ Caso Constantine y otros Vs. Trinidad y Tobago } \\
\hline \multicolumn{3}{|c|}{ * Confirmador de principio } \\
\hline \multicolumn{3}{|c|}{ Caso de las Hermanas Serrano Cruz Vs. El Salvador } \\
\hline \multicolumn{3}{|c|}{ * Confirmadora de principio } \\
\hline \multicolumn{3}{|c|}{ Caso Cantoral Huamaní y García Santa Cruz Vs. Perú } \\
\hline \multicolumn{3}{|c|}{ * Confirmadora de principio } \\
\hline \multicolumn{3}{|c|}{ Caso Heliodoro Portugal vs. Panamá } \\
\hline \multicolumn{3}{|c|}{ * Confirmadora de principio } \\
\hline \multicolumn{3}{|c|}{ Caso Tristán Donoso vs. Panamá } \\
\hline
\end{tabular}

\section{OBSERVACIONES FINALES CONCLUYENTES}

Si bien, la Corte Interamericana de Derechos Humanos, ha establecido en diferentes providen- cias, que las excepciones preliminares son un mecanismo de defensa, (CORIDH: 2005, 7 de marzo. prf, 30), porque no permiten el sometimiento del caso al fondo del asunto. No obstante, con la construcción de la línea jurisprudencial, se ha 
demostrado, que la excepción falta de competencia en razón a la materia, no ha sido en la mayoría de los casos efectiva ${ }^{20}$.

La inefectividad de la misma, se debe a la falta de apropiación por parte de los agentes estatales del precedente del sistema interamericano, proferido por la Corte Interamericana de Derecho Humanos. Véase como el Estado de Trinidad y Tobago, excepciona en el Caso Hilaire, la falta de competencia en razón a la materia y el fundamento de su defensa, es la reserva que le hace a la competencia de la Corte Interamericana, subordinando sus decisiones con relación a la Convención Americana, a lo establecido en la Constitución y/o a lo ordenado por los tribunales nacionales. En esta oportunidad, se evidenció del análisis de casos, que el máximo tribunal americano regional, le manifestó de forma clara, que no procedía la excepción porque la reserva era incompatible con el objeto y fin de la Convención, además que la Corte sí posee competencia para realizar un examen de los procesos internos a la luz de las garantías judiciales mínimas pero de la Convención, mas no de la normatividad interna. Sin embargo, el Estado de Trinidad y Tobago, no acató el precedente fijado por la Corte, y en los casos, Benjamin y Constantine, excepcionó exactamente lo mismo.

De la misma forma, en el caso Cantoral Huamani, el Estado de Perú, presenta la falta de apropiación de las decisiones anteriores del sistema interamericano y, de forma específica, las proferidas por la Corte IDH, al no tener presente que la excepción falta de competencia en razón a la materia, es improcedente cuando un Estado le ha concedido en el mismo escrito o por separado a la Corte, competencia para que se pronuncie sobre el cumplimiento o no del instrumento y, por ende, de la violación de los derechos contemplados en el mismo criterio establecido, cinco años antes en el Caso las Palmeras.

20 Para el presente artículo debe entenderse efectiva cuando la excepción es estimada en la Corte, es decir, la declarara admisible y no la desestima.
En otros términos, la efectividad de la excepción preliminar falta de competencia en razón a la materia, se presenta cuando el Estado logra demostrar, que el instrumento que está tratando hacer valer la Comisión y/o los Representantes de las víctimas, no ha sido ratificado por el Estado que excepciona, ó así lo haya ratificado, que en escrito separado no le concedió competencia a la Corte para que se pronuncie sobre la violación de los derechos humanos consagrados en el instrumento materia de litigio.

Sin embargo, lo que no podrán hacer los agentes estatales, es limitar la competencia contenciosa de la Corte, para que de un mayor alcance a lo consagrado en la Convención e interpretarla de forma armónica y complementaria con otros instrumentos del Sistema Interamericano o del Sistema Universal, cuando en la misma exista un vacio $y / o$ los hechos del caso lo requieran.

Entre tanto, la inefectividad se seguirá presentando cuando los agentes estatales sigan interponiendo la excepción falta de competencia en razón a la materia, con el fin que la Corte no revise las decisiones definitivas internas; que no conozca de pretensiones sobre reparaciones solicitadas por la Comisión; ó que los hechos materia de conflicto fueron ejecutados por agentes no estatales. Porque las mismas están destinadas a su desestimación e inadmisibilidad, restándole importancia a la presente excepción en el sistema, debido que el debate no se circunscribe en establecer, si un Estado le ha concedido a la Corte competencia con relación a un instrumento específico, sino a alegatos que deben ser analizados en el fondo del caso.

\section{BIBLIOGRAFÍA}

\section{Doctrina}

LOPEZ, D. (2008). El derecho de los jueces. (2 Ed.). Bogotá, Colombia: Editorial Legis.

BARBOSA, F. (2002). Litigio Interamericano. Bogotá, Colombia: Universidad Jorge Tadeo Lozano. 
BREWER, A. (2005). Mecanismos nacionales de protección de los derechos humanos: Garantías constitucionales de los derechos humanos en el derecho constitucional comparado latinoamericano. San José de Costa Rica: Instituto Interamericano de Derechos Humanos.

FAUNDEZ, H. (2006). El agotamiento de recursos internos en el sistema interamericano de protección de derechos humanos. Caracas, Venezuela: editorial Ex Libris.

NIKKEN, P. (2006). La Garantía Internacional de los derechos Humanos. Venezuela: Editorial Jurídica Venezolana.

\section{Instrumentos Internacionales}

CONVENCIÓN AMERICANA SOBRE DE DERECHOS HUMANOS. Suscrita en San José de Costa Rica el 22 de noviembre de 1969, en la Conferencia Especializada Interamericana sobre Derechos Humanos.

CONVENCIÓN INTERAMERICANA PARA PREVENIR Y SANCIONAR LA TORTURA. Adoptada en Cartagena de Indias, Colombia el 9 de diciembre de 1985, en el decimo quinto periodo ordinario de sesiones de la Asamblea General.

CONVENCIÓN INTERAMERICANA SOBRE DESAPARICIÓN FORZADA DE PERSONAS. Adoptada en Belém do Pará, Brasil el 9 de junio de 1994, en el vigésimo cuarto período ordinario de sesiones de la Asamblea General.

PROTOCOLO ADICIONAL A LA CONVENCIÓN AMERICANA SOBRE DERECHOS HUMANOS EN MATERIA DE DERECHOS ECONÓMICOS, SOCIALES Y CULTURALES "protocolo de san Salvador". Adoptado en El Salvador el 17 de noviembre de 1988.

REGLAMENTO DE LA COMISIÓN INTERAMERICANA DE DERECHOS HUMANOS. Aprobado por la Comisión en su $137^{\circ}$ período ordinario de sesiones, celebrado del 28 de octubre al 13 de noviembre de 2009.

REGLAMENTO DE LA CORTE INTERAMERICANA DE DERECHOS HUMANOS.
Aprobado por la Corte en su LXXXV período ordinario de sesiones, celebrado del 16 al 28 de noviembre de 2009.

\section{Jurisprudencia Corte Interamericana de Derechos Humanos}

Caso Alfonso Martín del Campo Dodd Vs. Estados Unidos Mexicanos. Sentencia de Excepciones Preliminares. Serie C No. 113. Sentencia de 03 de septiembre de 2004.

Caso Baldeón García Vs Perú. Sentencia Fondo, Reparaciones y Costas. Serie C No 147. Sentencia de 6 de abril de 2006.

Caso Benjamin y otros Vs. Trinidad y Tobago. Sentencia Excepciones Preliminares. Serie C No 81. Sentencia de 1 de septiembre de 2001.

Caso Blake Vs. Guatemala. Sentencia Excepciones preliminares. Serie C No 27. Sentencia de 2 de julio de 1996.

Caso Cantoral Huamaní y García Santa Cruz Vs. Perú. Sentencia Excepciones Excepción Preliminar, Fondo, Reparaciones y Costas. Serie C No 167. Sentencia de 10 de julio de 2007.

Caso Castañeda Gutman Vs. México. Sentencia de Excepciones Preliminares, Fondo, Reparaciones y Costas. Serie C No. 184. Sentencia de 6 de agosto de 2008.

Caso Castillo Petruzzi y otros Vs. Perú. Sentencia Excepciones Preliminares. Serie C No 41. Sentencia de 4 de septiembre de 1998.

Caso Cayara Vs. Perú. Sentencia de Excepciones Preliminares. Serie C No 24. Sentencia de 3 de febrero de 1993.

Caso Constantine y otros Vs. Trinidad y Tobago. Sentencia Excepciones Preliminares. Serie C No 82. Sentencia de 1 de septiembre de 2001.

Caso del Penal Miguel Castro Castro Vs Perú. Sentencia Fondo, Reparaciones y Costas. Serie C No 160. Sentencia de 25 de noviembre de 2006.

Caso de las Hermanas Serrano Cruz Vs. El Salvador. Sentencia Excepciones Preliminares. 
Serie C No 118. Sentencia de 23 de noviembre de 2004.

Caso de los Hermanos Gómez Paquiyauri Vs. Perú. Sentencia Fondo, Reparaciones y Costas. Serie C No. 110. Sentencia de 8 de julio de 2004.

Caso de la Masacre de Mapiripán Vs Colombia. Sentencia de Excepciones Preliminares. Serie C No 122. Sentencia del 7de marzo de 2005.

Caso de los "Niños de la Calle" (Villagrán Morales y otros) Vs. Guatemala. Sentencia de Fondo. Serie C No 63. Sentencia de 19 de noviembre de 1999.

Caso de la "Panel Blanca" (Paniagua Morales y otros) Vs. Guatemala. Sentencia de Fondo. Serie C No 37. Sentencia de 8 de marzo de 1998.

Caso Escher y Otros vs. Brasil. Sentencia de Excepciones preliminares, Fondo, Reparaciones y Costas. Serie C No. 200. Sentencia de 6 de julio de 2009.

Caso Gutiérrez Soler Vs Colombia. Sentencia Fondo, Reparaciones y Costas. Serie C No 132. Sentencia de 12 de septiembre de 2005.

Caso Heliodoro Portugal vs. Panamá. Sentencia Excepciones Preliminares, Fondo, Reparaciones y Costas. Serie C No 186. Sentencia de 12 de Agosto de 2008.

Caso Hilaire Vs. Trinidad y Tobago. Sentencia Excepciones Preliminares. Serie C No 80. Sentencia de 1 de septiembre de 2001.

Caso "Instituto de Reeducación del Menor" Vs. Paraguay. Sentencia Excepciones Preliminares, Fondo, Reparaciones y Costas. Serie C No. 112. Sentencia de 2 de septiembre de 2004.

Caso Las palmeras Vs Colombia. Excepciones Preliminares. Serie C No 67. Sentencia 4 de febrero de 2000.

Caso Tibi Vs. Ecuador. Sentencia de Excepciones Preliminares, Fondo, Reparaciones y Costas. Serie C No. 114. Sentencia de 7 de septiembre de 2004.

Caso Tristán Donoso Vs. Panamá. Sentencia de Excepciones Preliminares, Fondo, Reparaciones y Costas. Serie C No. 193. Sentencia de 27 de enero de 2009.

Caso Vargas Areco Vs Paraguay. Sentencia Fondo, Reparaciones y Costas. Serie C No 155. Sentencia de 26 de septiembre de 2006. 